\title{
Microarray Analysis of the Effects of Amelogenin on U937 Monocytic Cells
}

\author{
Terukazu Sanui*, Takao Fukuda*, Kensuke Yamamichi, Kyosuke Toyoda, Urara Tanaka, \\ Karen Yotsumoto, Takaharu Taketomi, Fusanori Nishimura
}

\author{
Department of Periodontology, Division of Oral Rehabilitation, Faculty of Dental Science, Kyushu University, Fukuoka, Japan \\ Email: *sanuteru@dent.kyushu-u.ac.jp, *tfukuda@dent.kyushu-u.ac.jp,yamamichi.k@dent.kyushu-u.ac.jp, \\ kyotoyo@dent.kyushu-u.ac.jp, urara@dent.kyushu-u.ac.jp, k-yotsumoto0812@dent.kyushu-u.ac.jp, \\ taketomi@med.kurume-u.ac.jp, fusanori@dent.kyushu-u.ac.jp
}

How to cite this paper: Sanui, T., Fukuda, T., Yamamichi, K., Toyoda, K., Tanaka, U., Yotsumoto, K., Taketomi, T. and Nishimura, F. (2017) Microarray Analysis of the Effects of Amelogenin on U937 Monocytic Cells. American Journal of Molecular Biology, 7, 107-122.

https://doi.org/10.4236/ajmb.2017.72009

Received: February 23, 2017

Accepted: April 27, 2017

Published: April 30, 2017

Copyright (c) 2017 by authors and Scientific Research Publishing Inc. This work is licensed under the Creative Commons Attribution International License (CC BY 4.0).

http://creativecommons.org/licenses/by/4.0/

\begin{abstract}
Periodontal diseases are chronic inflammation caused by particular types of bacteria and have been recognized as a cause of tooth loss in adults. These bacteria which invade periodontal tissue are phagocytosed mainly by monocytes and macrophages in this immune response, and will be presented to lymphocytes. Recently, therapies for regenerating periodontal tissues have been used extensively to treat periodontal disease, and in particular, enamel matrix derivative (EMD) is commonly used for such therapies in Japan. Amelogenin is a type of the extracellular matrix protein that accounts for $90 \%$ of the constituents of EMD. In this study, we carried out a detailed microarray analysis in order to evaluate a gene group involved in amelogenin stimuli in the human monocytic cell line U-937. Microarray analysis revealed that statistically significant changes were apparent in 273 genes (163 up-regulated and 110 down-regulated) subsequent to $4 \mathrm{~h}$ of amelogenin stimulation. The most highly enriched categories included "cell cycle", "DNA replication", and "DNA repair" in up-regulated annotation terms. On the other hand, "type I diabetes mellitus", "allograft rejection", and "graft versus host disease" were observed in down-regulated annotation terms. Specifically, the gene expression of major to compatibility complex (MHC) class I/II and CD80/86 was impaired in U937 cells after stimulation with amelogenin. In addition, the results of heat-map showed that the gene expression of inflammatory cytokine such as tumor necrosis factor (TFN), interleukin-18 (IL-18), and CXCL16 was markedly decreased after stimulation of monocytes with amelogenin. In conclusion, the findings of our study showed that by inducing monocyte growth through the suppression of the antigen-presenting ability of U937 cells, amelogenin may affect the immune responses of periodontal tissues originating from monocytes. Examining the effects of amelogenin on the transformation of macrophages differentiating from monocytes may establish a molecular ba-
\end{abstract}


sis for the anti-inflammatory effect of amelogenin in periodontal tissues.

\section{Keywords}

Human Monocyte, Periodontal Disease, Amelogenin, Microarray, Heat-Map

\section{Introduction}

Periodontal diseases are chronic inflammation caused by particular types of periodontal disease-causing bacteria. Because they cause resorption of the alveolar bone, they have been recognized as a cause of tooth loss in adults aged 40 years or older [1]. Teeth are supported by surrounding tissues known as periodontal tissues and are composed of four types of tissues: gingival soft tissue; periodontal ligament around the dental root; cementum, comprising the hard tissue at the surface of the dental root; and alveolar bone [2]. Treatment of periodontal disease has mainly consisted of removing the causative lesion, such as tooth-brushing instruction aimed at improving the condition of the oral cavity through cleaning, or removal of subgingival calculi by periodontal scaling and root planing or flap surgery. The main purpose of these treatments is to suppress the progression of periodontal disease [3]. However, recently developed regenerative therapies aimed at regenerating periodontal tissues have been used extensively to treat periodontal disease, and some success has been achieved [4]. In Japan, enamel matrix derivative (EMD) extracted from the tooth germs of young pigs is commonly used for such therapies. EMD has been commercialized under the name Emdogain ${ }^{\circledR}$ gel [5]. Among periodontal tissue regeneration materials that contain bioactive proteins such as growth factors, Emdogain ${ }^{\circledR}$ gel is currently the only treatment approved by the Japanese Ministry of Health, Labour and Welfare. However, although numerous studies have attempted to determine the mechanism of action of EMD, the molecular aspects of periodontal tissue regeneration at the signal transduction level remain unclear. Additionally, periodontal surgical treatment using EMD has been empirically shown to promote healing and is associated with reduced pain and swelling [6]. Previous reports have shown that amelogenin had an anti-inflammatory effect from the perspective of pro-inflammatory and anti-inflammatory cytokine production [7].

Amelogenin is a type of the extracellular matrix protein that accounts for $90 \%$ of the constituents of EMD and is a primary molecule in periodontal tissue regeneration using EMD [8]. In the field of medicine, extracellular matrix has been applied to wound healing and regenerative therapy, and amelogenin has been used to treat refractory pressure ulcers under the trade name Xelma ${ }^{\circledR}$ [9]. The practical application of amelogenin in periodontal tissue regeneration was developed based on the biological imitation of the dental development environment [10]. Amelogenin is secreted by ameloblasts during the formation of tooth germs and is thought to be involved in periodontal tissue formation, beginning with cementum which is deposited in the dentin [11]. Amelogenin-knockout 
mice exhibited cementum hypoplasia and abnormal differentiation of osteoclasts in their oral cavity [12]. Recombinant amelogenin has been reported to cause periodontal tissue regeneration in laboratory animals [13]. In periodontal ligament cells and osteoblasts, which are important for periodontal tissue regeneration, amelogenin-associated molecules should be identified in order to establish the molecular basis of their effects. By proteomic analysis focusing on amelogenin, which is a major protein in EMD, we identified a new group of amelogenin-associated molecules such as Grp78 in osteoblasts [14]. In addition, the association between amelogenin (rM180) and Grp78 has been reported to be involved in the cellular migratory capacity of periodontal ligament stem cells [15].

When periodontal disease-causing bacteria invade periodontal tissues, oral bacteria are phagocytosed by neutrophils in a non-specific manner in order to confer protection to the host. However, if this is the only protection and if it is insufficient, the organism will develop a full immune response. In this immune response, antigens are phagocytosed mainly by monocytes and macrophages and will be presented to lymphocytes (antigen-presenting reaction). This explains why monocytes are considered the basis of the immune responses. In our study, we examined the effects of amelogenin on immune responses. We carried out a detailed microarray analysis in order to evaluate a gene group involved in amelogenin stimuli in the human monocytic cell line U-937.

\section{Materials and Methods}

\subsection{Cell Culture}

U937 human monocytic cell line was purchased from RIKEN BioResouce Center (Ibaraki, Japan). U937 cells were cultured in RPMI-1640medium containing 10\% heat-inactivated fetal bovine serum (FBS), penicillin, and streptomycin at $37^{\circ} \mathrm{C}$ in a $5 \% \mathrm{CO}_{2}$ incubator. Cells were sub-cultured every $48-72 \mathrm{~h}$, inoculum being 5 $\times 10^{5} / \mathrm{ml}$ and cell viability (>95\%) was confirmed by trypan blue exclusion.

\subsection{Recombinant Protein}

Cloning and expression of a glutathione $S$-transferase (GST) full-length recombinant amelogeninfusion (GST-rM180), and the purification of rM180 were previously described [14]. Removal of endotoxin from rM180 was confirmed by Limulus Amebocyte Lysate Assay (Endotoxin Level: $10 \mu \mathrm{g}$ of rM180 $<0.03 \mathrm{EU})$. U937 cells were stimulated with $\mathrm{rM180}(10 \mu \mathrm{g} / \mathrm{mL})$ for $4 \mathrm{~h}, 8 \mathrm{~h}, 12$ $\mathrm{h}$, and $24 \mathrm{~h}$.

\subsection{Gene Expression Profiling by Microarray}

Total RNA was isolated with Isogen 2 (Nippon Gene, Tokyo, Japan) and purified from U937 cells using an RNeasy Mini Kit (Qiagen, Valencia, CA). Subsequent hybridization and microarray analysis were conducted at the Research Support Center, Kyushu University Graduate School of Medical Sciences according to the manufacture's recommended protocols. Briefly, RNA integrity was verified 
using BioRad Experion (Bio-Rad Laboratories, Hercules, CA) by measuring the ratio of band intensity between the $28 \mathrm{~S}$ and $18 \mathrm{~S}$ rRNA. The RNA integrity number (PRN) was close to 10 for all samples. Total RNA (200 ng) was converted to biotinylated cRNA using an Illumina TotalPrep RNA Amplification Kit (Life Technologies, Foster City, CA, USA). Next, a total of 750 ng of biotinylated-cRNA was overlaid onto individual array spots of the HumanHT-12 v4 BeadChip (Illumina, San Diego, CA, USA). The chip was hybridized at $58^{\circ} \mathrm{C}$ for $18 \mathrm{~h}$, washed, stained with fluorescent reagents, and scanned using a BeadArray Reader (Illumina). Relative hybridization intensities and background hybridization values were calculated using Genome Studio v1.8 (Illumina). Using procedures recommended by Illumina, the raw signal intensities of five samples were normalized using quantile algorithms from the "lumi" [16] and "preprocess Core" library packages [17] on the Bioconductor software [18]. Probes flagged as "Detection P-value $<0.05$ " in at least one sample were selected for analysis. To identify genes that were up regulated or down regulated, we calculated the intensity-based Z-scores [19] and the ratios (non-log scaled fold-change) of the normalized signal intensities for each probe, comparing the control and experiment samples. Next, we established criteria for differentially expressed genes (DIGs): upregulated genes, $\mathrm{Z}$-score $\geq 2.0$ and ratio $\geq 1.5$-fold; down regulated genes, $\mathrm{Z}$-score $\leq-2.0$ and ratio $\leq 0.66$.

\subsection{Microarray Analysis}

To determine the cellular effects of these DIGs and significant pathway enrichment, we used the Database for Annotation, Visualization and Integrated Discovery (DAVID) software (http://david.abcc.ncifcrf.gov/home.jsp) [20]. To characterize the biological processes affected by DIGs, we used Gene Ontology (GO) and the functional annotation-clustering feature of DAVID. The functional annotation clustering tool measures the similarities between GO terms based on the extent of their associated genes, and assembles similar and redundant GO terms into annotation clusters. Each clustered GO term is assigned a Fisher Exact $P$-value representing the degree of enrichment of the GO term within the DIGs. Each cluster is assigned an enrichment score signifying its biological significance. A biologically significant cluster (high enrichment score) is generated only when the majority of the GO term members have significant enrichment values. Functional annotation clusters with an enrichment-score of $>1.3$ were considered significant [21], and the resulting clusters were further filtered to retain only those GO terms with $P$ values of $<0.05$. Kyoto Encyclopedia of Genes and Genomes (KEGG) pathway analysis was also performed to analyze the significance of biological functions identified in large-scale transcriptome data. In addition, we generated a heat-map using Multi Experiment Viewer (MeV) software (http://www.tm4.org/mev.html) [22] and a hierarchical clustering (HCL) method for gene sorting. The inflammation-associated genes were identified as GO terms containing "inflammatory response". Color indicates the distance from the median of each column. "Pearson correlation" and "average linkage 
clustering" were used to determine distance and linkage, respectively. Microarray data analysis was supported by Cell Innovator

(http://www.cell-innovator.com/).

\section{Results}

\subsection{Amelogenin Up-Regulates the Expression Profiles of Cell Proliferation-Associated Genes in U937 Cells}

To characterize the biological effects of amelogenin in monocytes, we performed transcriptional profiling of U937 cells using microarray analysis. Samples of U937 cells were stimulated with rM180 for $4 \mathrm{~h}, 8 \mathrm{~h}, 12 \mathrm{~h}$, or $24 \mathrm{~h}$. U937 cells in the absence of rM180 stimulation were used as the control sample (unstimulated). Scatter plot analyses of global gene expression compared with the control (unstimulated) demonstrated that $4 \mathrm{~h}$ of rM180 stimulation (unstimulated vs. rM$1804 \mathrm{~h}$ ) resulted in greater changes to gene expression than $24 \mathrm{~h}$ of stimulation (unstimulated vs. rM18024h) (Figure 1). Although amelogenin induced relatively early changes in transcriptional regulation, most of these were dissipated after $24 \mathrm{~h}$. Statistically significant changes were apparent in 273 DIGs (163 upregulated and 110 down-regulated) subsequent to $4 \mathrm{~h}$ of rM180 stimulation. We performed functional annotation clustering of the DIGs following $4 \mathrm{~h}, 8 \mathrm{~h}, 12 \mathrm{~h}$, and $24 \mathrm{~h}$ of amelogenin treatment to identify significantly up-regulated annotation terms (Table 1 and Figure 2). The most highly enriched categories included "cell cycle", "DNA replication", "DNA repair", and "ribosome". These results indicate that amelogenin induces the expression levels of genes encoding cell proliferation in U937 cells.

\subsection{Amelogenin down-Regulates the Expression Profiles of Antigen Presentation-Associated Genes in U937 Cells}

On the other hand, we also performed functional annotation clustering of the DIGs following 4, 8, $12 \mathrm{~h}$, and $24 \mathrm{~h}$ of rM180 treatment to identify significant down-regulated annotation terms (Table 2 and Figure 3 ). The most highly enriched categories included "type I diabetes mellitus", "allograft rejection", and "graft versus host disease". Specifically, the gene expression of major his to compatibility complex (MHC)class I/II and CD80/86 were impaired in U937 cells after stimulation with rM180 (Figure 3).

Our results showed that amelogenin inhibits the expression levels of genes encoding antigen presentation in U937 cells.

\subsection{Amelogenin Down-Regulates the Expression Profiles of Inflammation-Associated Genes in U937 Cells}

Since amelogenin plays an inhibitory role in the antigen presentation of U937 cells, we analyzed the effects of rM180 on the transcriptional profiles of inflammation-related genes. Five samples of U937 cells were categorized according to the period of rM180 stimulation ( $0 \mathrm{~h}, 4 \mathrm{~h}, 8 \mathrm{~h}, 12 \mathrm{~h}$, and $24 \mathrm{~h}$ ); and a clustered heat-map of the 106 inflammation-related genes was generated (Figure4(a)). 
unstimulated vs rM180 4h

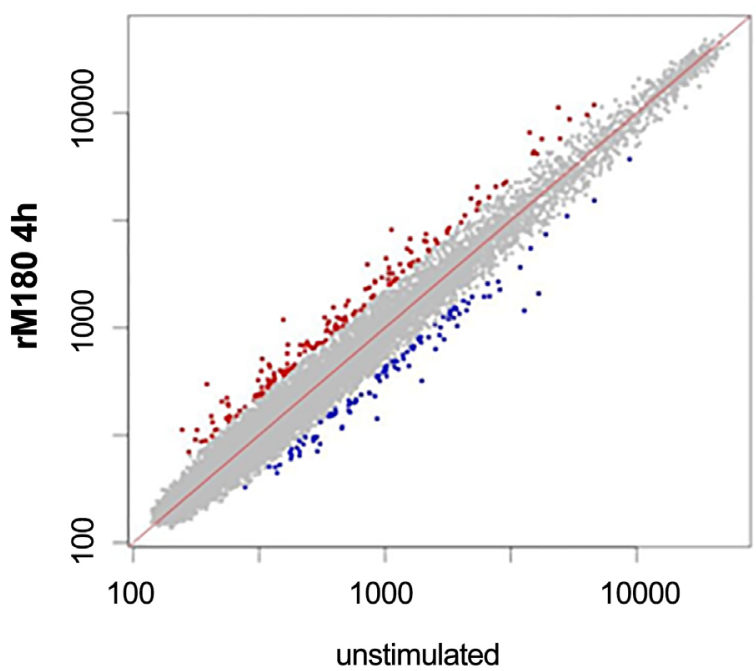

(a)

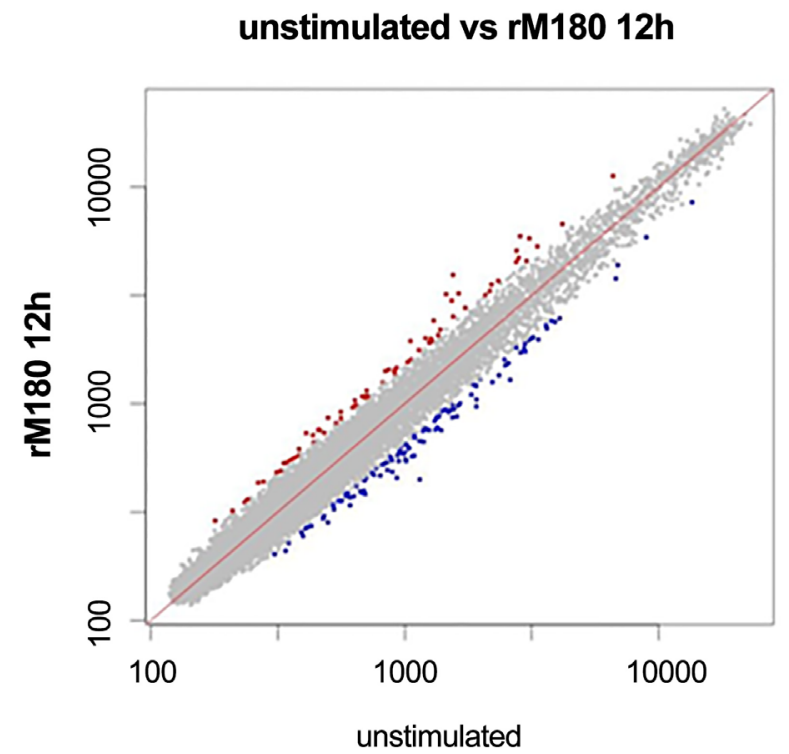

(c) unstimulated vs rM180 8h

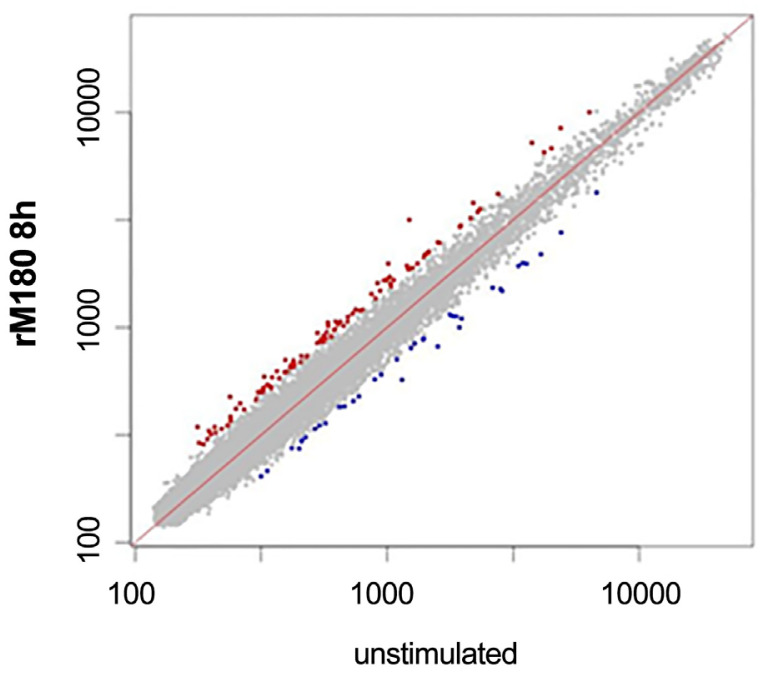

(b)

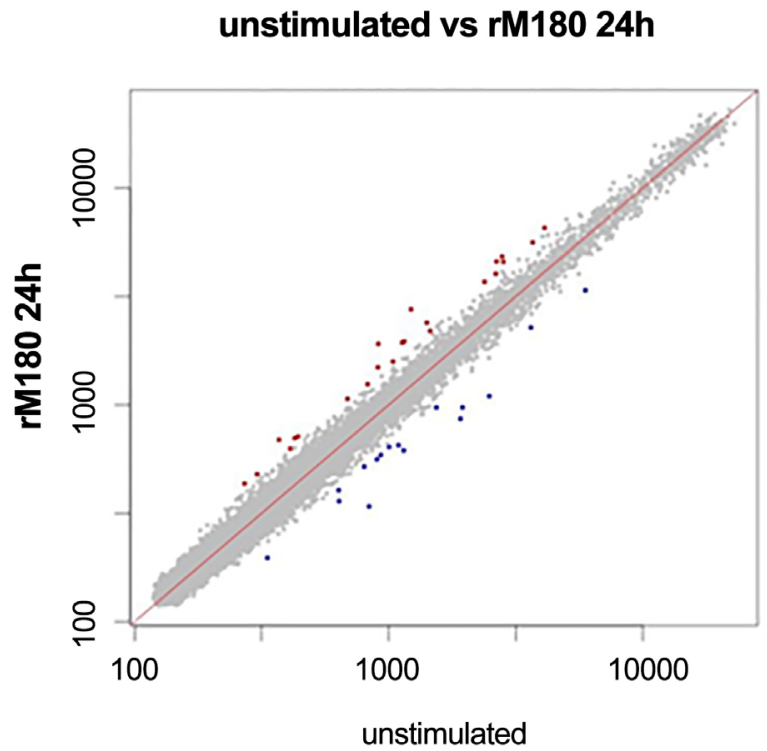

(d)

Figure 1. Scatter plots comparing global gene expression profiles confirming the effects of amelogenin treatment in U937 cells. (a)-(d) U937 cells were stimulated with rM180 (10 g/mL) for4 h (a); 8h (b), 12h (c); or 24h (d). The X-axis indicates the relative normalized $\log 2$-signal intensity of the unstimulated, and the Y-axis indicates the normalized $\log 2$-signal intensity of rM180 stimulated. Red dots denote upregulated genes (Z-score $\geq 2.0$ and ratio $\geq 1.5$-fold), and blue dots indicate downregulated genes $(Z$-score $\leq-2.0$ and ratio $\leq 0.66)$.

Subsequently, the 20 genes exhibiting a $>2$-fold difference between the four parameters at $4 \mathrm{~h}, 8 \mathrm{~h}, 12 \mathrm{~h}$, and $24 \mathrm{~h}$ were validated (Figure $4(\mathrm{~b})$ ). The gene expression of inflammatory cytokine and chemokine such as tumor necrosis factor (TFN), interleukin-18 (IL-18), and CXCL16 was markedly decreased at $4 \mathrm{~h}$ and 8 $\mathrm{h}$ after stimulation of monocytic cells with amelogenin. On the other hand, the gene expression of IL-8 peaked $4 \mathrm{~h}$ after the addition of rM180 and then gradually decreased in U937 cells. These findings indicated that amelogenin enhances 
the expression levels of genes encoding anti-inflammatory response in U937 cells.

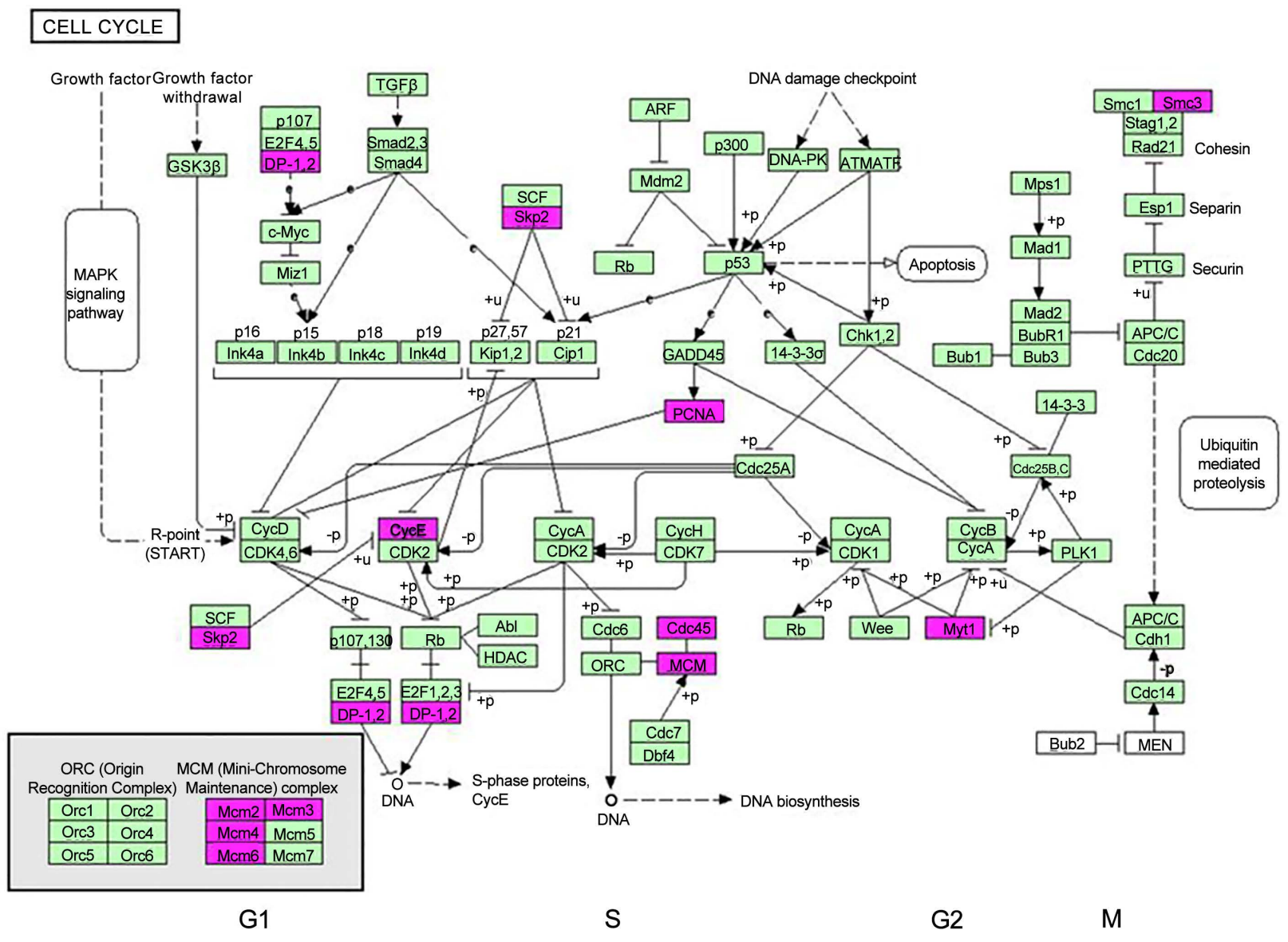

(a)

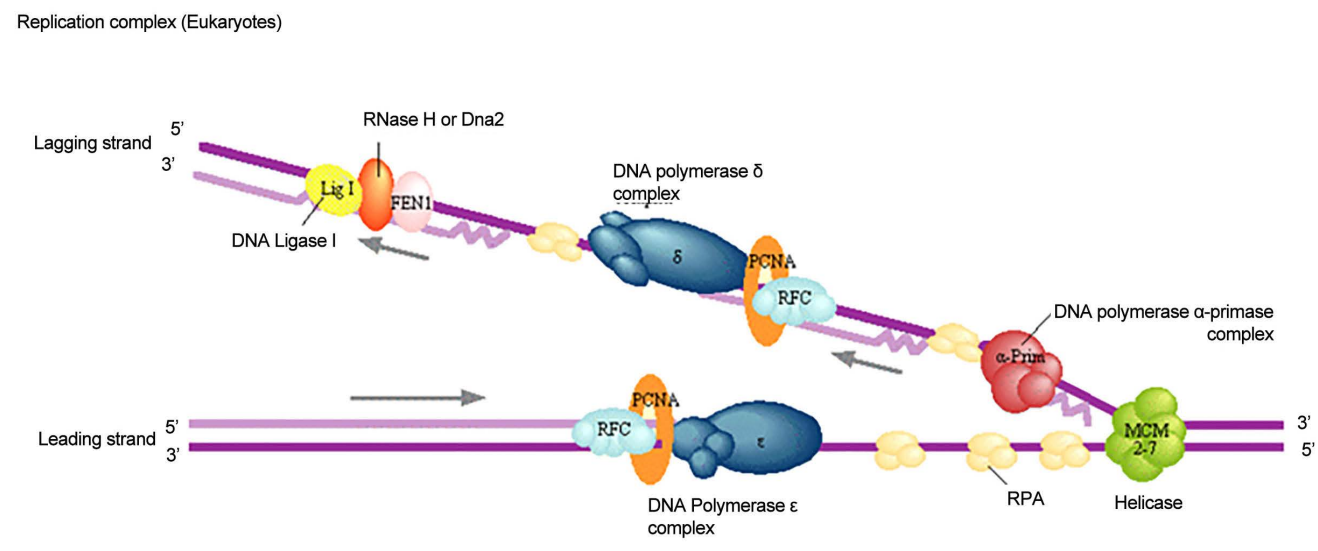

DNA polymerase $\alpha$-primase complex \begin{tabular}{|l|l|l|l|}
\hline a1 & a2 & Pri1 & Pri2 \\
\hline
\end{tabular}

DNA polymerase $\delta$ complex \begin{tabular}{|l|l|l|l|}
\hline$\delta 1$ & $\delta 2$ & $\delta 3$ & $\delta 4$ \\
\hline
\end{tabular}

DNA Polymerase $\varepsilon$ complex \begin{tabular}{|c|c|c|c|}
\hline$\varepsilon 1$ & $\varepsilon 2$ & $\varepsilon 3$ & $\varepsilon 4$ \\
\hline
\end{tabular}

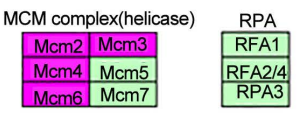

Clamp Clamploader \begin{tabular}{|l|l|l|}
\hline PCNA & RFC1 \\
\hline
\end{tabular}

RNaseHI RNaseHII ENaseH2A|RNaseH2IRRaseH2C

\begin{tabular}{|ll}
\multicolumn{1}{l}{ Hebcase } & \multicolumn{1}{c}{ DNA ligase } \\
\hline Dna2 & Fen1 \\
\hline
\end{tabular}

(b)

Figure 2. Representative KEGG Pathway Maps of cell cycle (a) and DNA replication (b) signaling which include up-regulated genes after stimulation of amelogenin for $4 \mathrm{~h}$. The grid with the round edge represents another pathway; the pink-marked nodes are associated with up-regulated genes ( $\mathrm{Z}$-score $\geq 2.0$ and ratio $\geq 1.5$-fold); the green nodes have no significance. 
Table 1. Functional annotation clustering predicted to be up-regulated after stimulation of rM180.

\begin{tabular}{|c|c|c|c|}
\hline Stimulation Time (h) & Term & Gene count & $P$-Value \\
\hline \multirow[t]{7}{*}{4} & Cell cycle & 11 & $5.4 \mathrm{E}-7$ \\
\hline & DNA replication & 7 & $1.6 \mathrm{E}-6$ \\
\hline & Spliceosome & 7 & $2.0 \mathrm{E}-3$ \\
\hline & Mismatch repair & 3 & $2.4 \mathrm{E}-2$ \\
\hline & Base excision repair & 3 & $5.3 \mathrm{E}-2$ \\
\hline & Nucleotide excision repair & 3 & $7.9 \mathrm{E}-2$ \\
\hline & Proteasome & 3 & $8.8 \mathrm{E}-2$ \\
\hline \multirow[t]{2}{*}{8} & Spliceosome & 3 & $2.1 \mathrm{E}-3$ \\
\hline & Cell cycle & 4 & $1.8 \mathrm{E}-2$ \\
\hline \multirow[t]{2}{*}{12} & Non-small cell lung cancer & 3 & $4.5 \mathrm{E}-3$ \\
\hline & Cell cycle & 5 & $3.5 \mathrm{E}-2$ \\
\hline 24 & Ribosome & 3 & $1.7 \mathrm{E}-2$ \\
\hline
\end{tabular}

DAVID v6.7 functional annotation bioinformatics microarray analysis software was used to obtain the functional annotation clustering. Only GO pathway terms that showed statistically significantly differences in the amount of genes (compared unstimulated vs. rM180 4h, $8 \mathrm{~h}, 12 \mathrm{~h}$, and $24 \mathrm{~h})$ are shown $(P$-value $\leq$ $0.05)$.

\section{Discussion}

When considering the onset of periodontal diseases, it may appear that oral bacteria act as antigens and initiate an inflammation reaction; however, the constituents of oral bacteria, namely their outer membrane proteins, pili, and lipopolysaccharides, have a diverse range of antigenicity [23]. In addition, they activate living cells through various receptors in the cells. When oral bacteria invade the periodontal tissue, neutrophils protect the host organism by nonspecific phagocytosis of the oral bacteria; when this does not confer sufficient protection, a full-fledged immune response develops. In the immune response, the antigens are mainly phagocytosed by monocytes and macrophages, followed by antigen presentation to lymphocytes. Thus, monocytes are considered the origin of immune responses. Additionally, the lipopolysaccharides of gram-negative bacteria have a strong activating effect on monocytes [24] and are important for determining the etiopathology of periodontal diseases involving inflammation and infection due to gram-negative bacteria. The amelogenin used in this study was a recombinant protein from Escherichia coli, but because Triton $\mathrm{X}$ was used in the purification process, the level of endotoxin was confirmed to be $0.03 \mathrm{EU} / \mathrm{L}$ or lower when $10 \mathrm{mg}$ amelogenin was used; therefore, the stimulatory effect of amelogenin on monocytes with lipopolysaccharides from $E$. coli was negligible.

In scatter plot analysis aimed at confirming the temporal changes in gene expression caused by amelogenin stimuli, our findings showed that unlike cytokines, amelogenin did not induce notable variations in gene expression; our findings also confirmed that the effects of amelogenin generally developed at a 


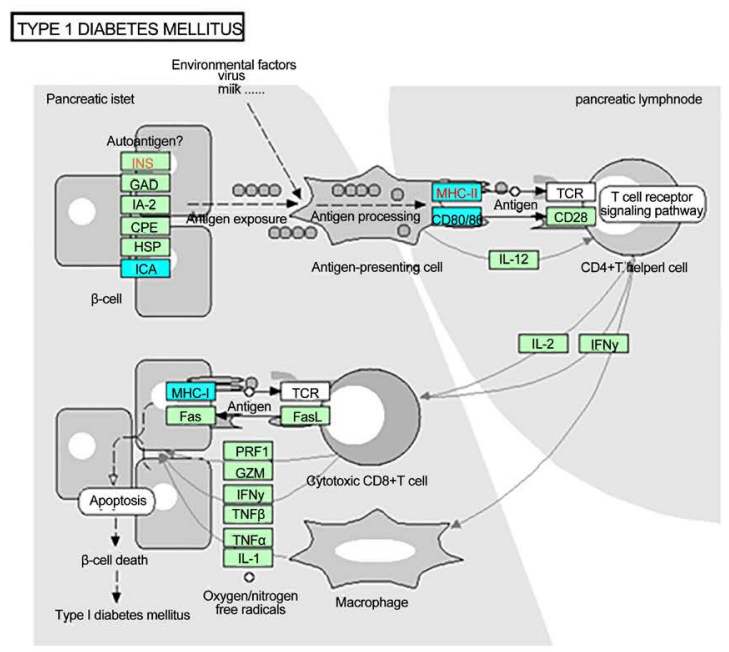

(a)

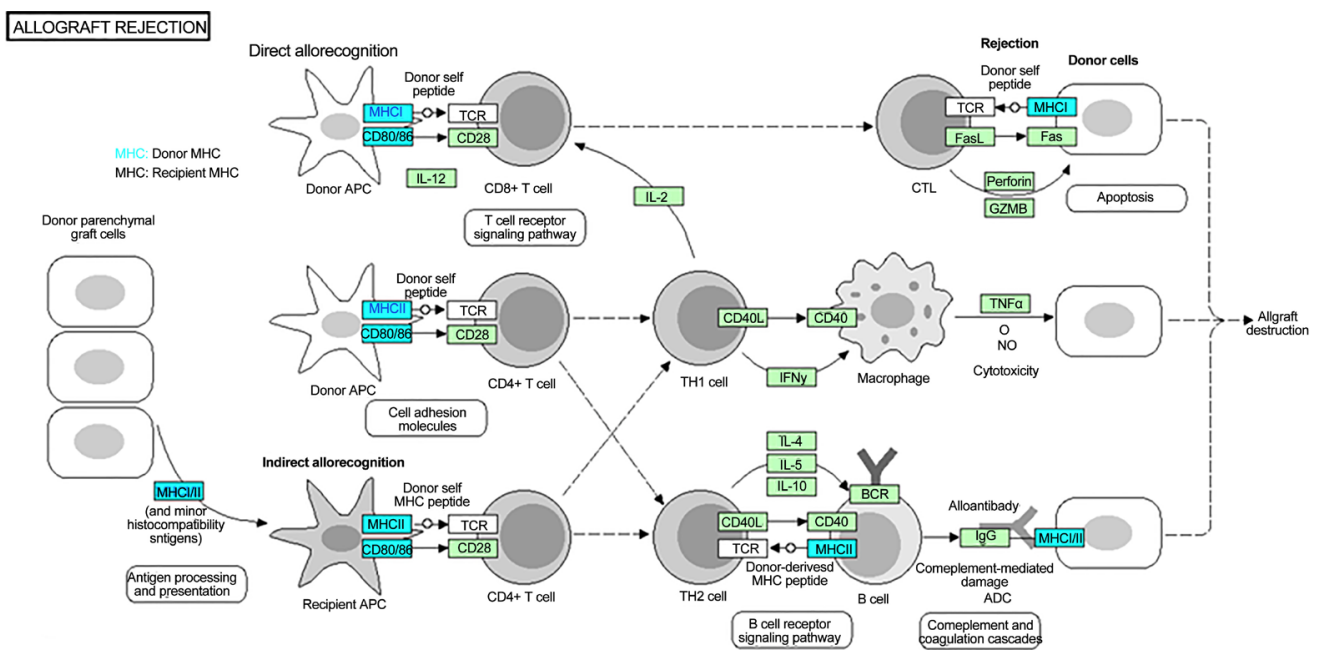

(b)

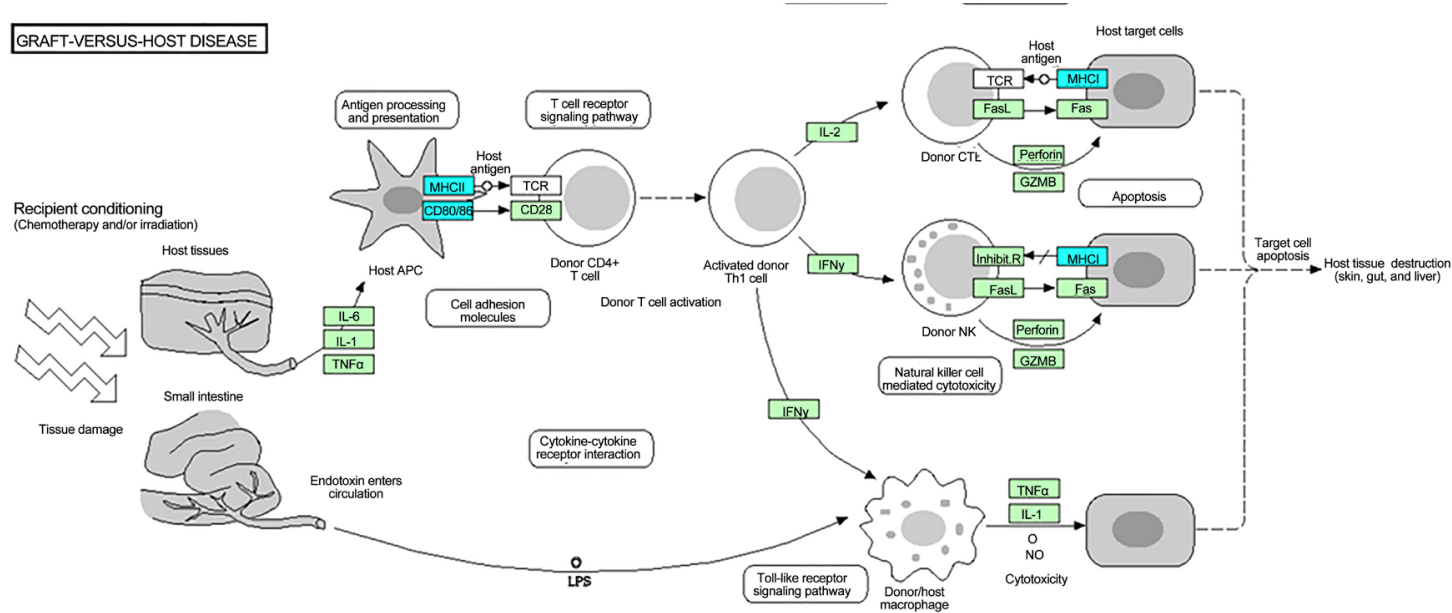

(c)

Figure 3. Representative KEGG Pathway Maps of type 1 diabetes mellitus (a), allograft rejection (b), and graft versus host disease (c) signaling which include down-regulated genes after stimulation of amelogenin for $4 \mathrm{~h}$. The grid with the round edge represents another pathway; the blue-marked nodes are associated with downregulated genes (Z-score $\leq-2.0$ and ratio $\leq 0.66$ ); the green nodes have no significance. 
Color Key

Distance from median

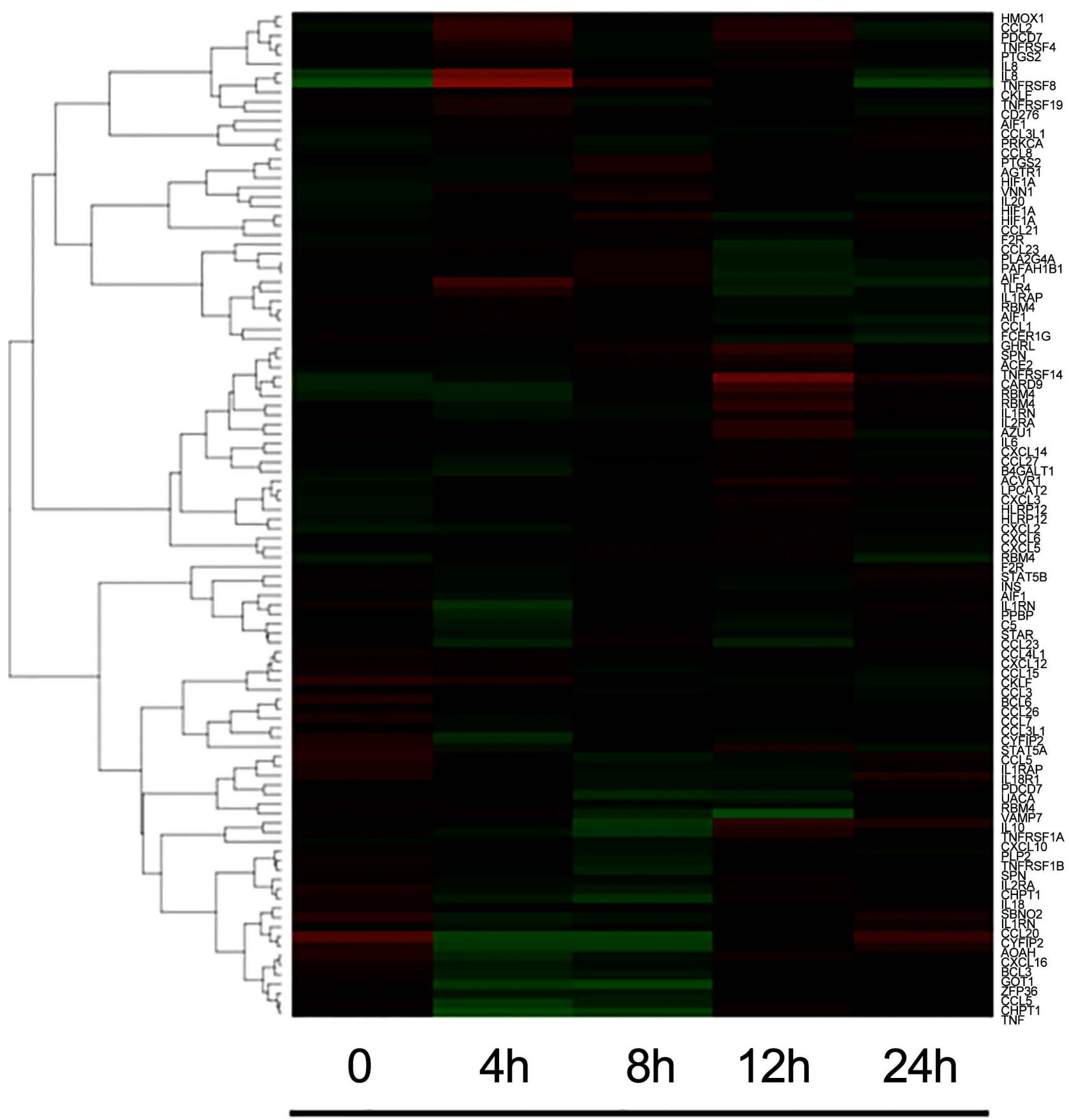

rM 180 stimulation

(a) 


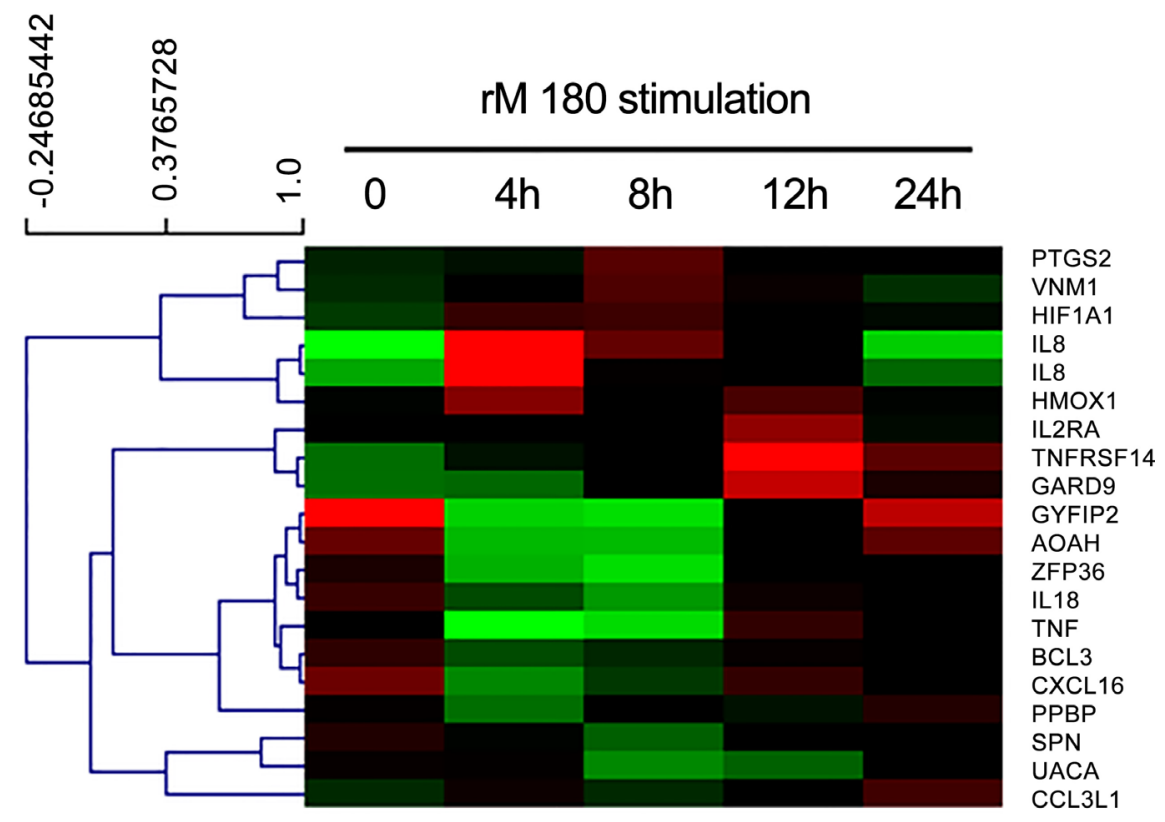

(b)

Figure 4. The expression profiles of amelogenin-induced cell function genes in U937 cells. (a) The clustering diagram and heatmap of gene trees were generated using MeV software. Five samples of U934 cells were categorized according to the period of amelo-genin stimulation ( $0 \mathrm{~h}, 4 \mathrm{~h}, 8 \mathrm{~h}, 12 \mathrm{~h}$ and $24 \mathrm{~h}$ ). Hierarchical clustering (HCL) was employed to sort the genes (using "Pearson correlation", and "average linkage clustering"). Each row represents a sample and each column represents a gene. Inflam-mation-associated genes were extracted using a Gene Ontology (GO) term containing "inflammatory response". The color gradient indicates the distance from the median of each column. Red blocks represent high expression, and green blocks, low expression relative to the unstimulated sample; black blocks indicate similar expression; (b) Heatmap illustrating the expression of selected genes in the four U937 cell groups. Discernible genes $(|\log \mathrm{FC}| \geq 0.5)$ were extracted by converting the ratio of inflam-mationrelated genes. A red band indicates high relative expression and a green band indicates low relative expression.

relatively early stage (4h) (Figure 1). We previously reported that the growth of osteoblasts and the migration of periodontal ligament stem cells were enhanced by amelogenin [14] [15]. In other studies, amelogenin was reported to enhance the differentiation of cementoblasts as well as that of periodontal ligament cells; however, the results of the present study suggest that amelogenin promotes cell growth mainly by enhancing the gene expression of proliferating cell nuclear antigen, CycE, and Cdc45 in monocytes (Figure 2). Amelogenin has been reported to exert various effects depending on the cell type and stage of differentiation; in addition, Emdogain Gel has been reported to enhance the growth and differentiation of osteoblasts, cementoblasts, and periodontal ligament cells, and to inhibit the in growth of gingival epithelial cells toward bony defects [25]. The U-937 cells used in this study were monocytic cells; the effects after differentiation of these cells into macrophages should be examined in future studies. Previous clinical reports have shown that while the periodontal tissue regeneration effect of Emdogain persisted over a few years, the microarray analyses results revealed that the stimulatory effect of amelogenin on monocytes was limited to the early stages. This is thought to be because monocytes were floating cells and that amelogenin was not affected as a scaffold for the extracellular matrix. 
Table 2. Functional annotation clustering predicted to be down-regulated after stimulation of rM180.

\begin{tabular}{|c|c|c|c|}
\hline Stimulationtime (h) & Term & Gene count & $P$-Value \\
\hline \multirow[t]{9}{*}{4} & Type I diabetes mellitus & 5 & $3.0 \mathrm{E}-4$ \\
\hline & Ribosome & 6 & $5.4 \mathrm{E}-4$ \\
\hline & Viral myocarditis & 5 & $2.2 \mathrm{E}-3$ \\
\hline & Allograft rejection & 4 & $2.7 \mathrm{E}-3$ \\
\hline & Graft-versus-host disease & 4 & $3.4 \mathrm{E}-3$ \\
\hline & Autoimmune thyroid disease & 4 & $7.2 \mathrm{E}-2$ \\
\hline & Cell adhesion molecules & 5 & $1.9 \mathrm{E}-2$ \\
\hline & Intestinal immune network for IgA production & 3 & $5.6 \mathrm{E}-2$ \\
\hline & Natural killer cell modified cytotoxicity & 4 & $8.6 \mathrm{E}-2$ \\
\hline \multirow[t]{4}{*}{8} & Terpenoid backbone biosynthesis & 2 & $3.2 \mathrm{E}-2$ \\
\hline & Allograft rejection & 2 & $7.5 \mathrm{E}-2$ \\
\hline & Graft-versus-host disease & 2 & $8.1 \mathrm{E}-2$ \\
\hline & Type I diabetes mellitus & 2 & $8.7 \mathrm{E}-2$ \\
\hline \multirow[t]{3}{*}{12} & Ribosome & 4 & $1.4 \mathrm{E}-3$ \\
\hline & Valine, leucine and isoleucine degradation & 3 & $2.7 \mathrm{E}-2$ \\
\hline & Terpenoid backbone biosynthesis & 2 & $8.5 \mathrm{E}-2$ \\
\hline 24 & n.p & - & - \\
\hline
\end{tabular}

DAVID v6.7 functional annotation bioinformatics microarray analysis software was used to obtain the functional annotation clustering. Only GO pathway terms that showed statistically significantly differences in the amount of genes (compared unstimulated vs. rM180 4h, $8 \mathrm{~h}, 12 \mathrm{~h}$, and $24 \mathrm{~h})$ are shown $(P$-value $\leq$ $0.05)$.

The pathways inhibited by amelogenin may include antigen presentation pathways such as MHC class I/II and CD80/86 (Figure 3). Generally, the process of cell growth and differentiation includes a number of conflicting issues, and our findings showed that because of the proliferative effect of amelogenin on monocytes, amelogenin may have inhibited the latter's differentiation into macrophages responsible for antigen presentation. In addition, candidate pathways for the stimulation of monocytes by amelogenin include intracellular uptake through phagocytosis and endocytosis and receptor-mediated signal transduction. However, because of the impaired antigen-presenting ability, the phagocytic pathway is highly likely to be excluded. We previously reported that GRP78 on the cell membrane of periodontal ligament stem cells served as a receptor for amelogenin [15]. GRP78 is a ubiquitous chaperone protein present mainly in the endoplasmic reticulum [26], but in undifferentiated stem cells, it is also expressed on the cell membrane [27] and has been reported to function as a receptor for Cript [28] and DMP1 [29]. GRP78 is also thought to be expressed in the U-937 cell line composed of monocytes, but no previous studies have evaluated the expression of GRP78 on the cell membrane during the differentiation process. Amelogenin is likely phagocytosed by macrophages; however, further studies are needed to examine the expression of GRP78 on the cellular mem- 
brane of monocytes and other cells involved in immune responses, as well as the possibility that GRP78may be a receptor for amelogenin.

Clinical reports of the use of Emdogain suggested that amelogenin has an anti-inflammatory effect [7] [30]; however, whether the inhibitory effect of amelogenin on the antigen-presenting ability of monocytes is directly linked to its immunosuppressive effect remain unclear. The clustered heat-map assay revealed that the inflammation-related gene expression of IL-8 was enhanced and that of TNF- $\alpha$ was reduced at the early stage $(4 \mathrm{~h})$ after amelogenin stimulation (Figure 4(b)). It is interesting that inflammatory cytokine TNF- $\alpha$ was suppressed by amelogenin in U937 cells whileIL-8 was also known as neutrophil chemotactic factor. The early stages of the inflammatory process are essential for tissue repair and regeneration; if the subsequent series of events, including the resolution of the inflammation, does not occur, the condition will persist as chronic inflammation. Because amelogenin exerted a growth-enhancing effect and chemotaxis/angiogenesis induced by IL-8 on monocytes [31], an increasing number of macrophages leaked out of blood vessels and accumulated in tissues; thus, shortening the period until the resolution of inflammation with the inhibition of TNF- $\alpha$ should be examined. Additionally, we found that amelogenin stimulation suppressed the expression of interleukin-18 (IL-18) [32] which induces the production of interferon- $\gamma$ (IFN- $\gamma$ ) at an early stage (4h). IL-18 inhibitionmay be involved in the down-regulation of MHC class II by amelogenin stimuli since the expression of MHC class II is induced by IFN- $\gamma$ [33]. The effects of amelogenin on the transformation and functions of macrophages require further analysis because monocytic cell lines before differentiation were used in this study. In addition, gingival fibroblasts are host cells involved in the construction of periodontal connective tissues, but around monocytes, they control the environment of periodontal tissues. Therefore, while the extracellular matrix is produced in healthy periodontal tissues, the matrix produces substrate-degrading enzymes such as collagenases while regulating its own synthesis and degradation, thereby constantly restructuring the gingival tissues [34]. However, when an inflammatory substance spreads in the connective tissues and causes periodontal disease, gingival fibroblasts become the target cells of various cytokines produced by immunocompetent cells such as monocytes [35] [36]. In addition, gingival fibroblasts produce various cytokines and play a role in some cytokine networks [37]. Thus, at the site of the inflammation in the connective tissue, gingival fibroblasts control and regulate the periodontal tissue environment to efficiently establish immune responses.

In conclusion, the findings of our study showed that by inducing monocyte growth through the suppression of the antigen-presenting ability of these cells, amelogenin may affect the immune responses of periodontal tissues originating from monocytes. Examining the effects of amelogenin on the transformation of macrophages differentiating from monocytes, as well as on gingival fibroblasts, may establish a molecular basis for the anti-inflammatory effect of amelogenin in periodontal tissues. 


\section{Acknowledgements}

This work was supported by Grants-in-Aid for Scientific Research C (26463136) from the Japan Society for the Promotion of Science, Takeda Science Foundation. Technical support was provided from the Research Support Center, Graduate School of Medical Sciences, Kyushu University.

\section{Disclosure}

The authors have no conflicts of interest to disclose.

\section{References}

[1] Flemming, T.F. (1999) Periodontitis. Annals of Periodontology, 4, 32-37. https://doi.org/10.1902/annals.1999.4.1.32

[2] Hassell, T.M. (1993) Tissues and Cells of the Periodontium. Periodontology 2000, 3, 9-38. https://doi.org/10.1111/j.1600-0757.1993.tb00230.x

[3] Slots, J. (2013) Periodontology: Past, Present, Perspectives. Periodontology 2000, 62, 7-19. https://doi.org/10.1111/prd.12011

[4] Ramseier, C.A., Rasperini, G., Batia, S. and Giannobile, W.V. (2012) Advanced Reconstructive Technologies for Periodontal Tissue Repair. Periodontology 2000, 59, 185-202. https://doi.org/10.1111/j.1600-0757.2011.00432.x

[5] Sculean, A., Kiss, A., Miliauskaite, A., Schwarz, F., Arweiler, N.B. and Hannig, M. (2008) Ten-Year Results Following Treatment of Intra-Bony Defects with Enamel Matrix Proteins and Guided Tissue Regeneration. Journal of Clinical Periodontology, 35, 817-824. https://doi.org/10.1111/j.1600-051X.2008.01295.x

[6] Jepsen, S., Heinz, B., Jepsen, K., Arjomand, M., Hoffmann, T., Richter, S., et al. (2014) A Randomized Clinical Trial Comparing Enamel Matrix Derivative and Membrane Treatment of Buccal Class II Furcation Involvement in Mandibular Molars. Part I: Study Design and Results for Primary Outcomes. Journal of Periodontology, 75, 1150-1160. https://doi.org/10.1902/jop.2004.75.8.1150

[7] Almqvist, S., Werthén, M., Lyngstadaas, S.P., Gretzer, C. and Thomsen, P. (2012) Amelogenins Modulate Cytokine Expression in LPS-Challenged Cultured Human Macrophages. Cytokine,58, 274-279.

[8] Chen, E., Piddington, R., Decker, S., Park, J., Yuan, Z.A., Abtams, W.R., et al. (1994) Regulation of Amelogenin Gene Expression during Tooth Development. Developmental Dynamics, 199, 189-198. https://doi.org/10.1002/aja.1001990304

[9] Romanelli, M., Dini, V., Vowden, P. and Agren, M.S. (2008) Amelogenin, an Extracellular Matrix Protein, in the Treatment of Venous Leg Ulcers and Other Hard-toHeal Wounds: Experimental and Clinical Evidence. Clinical Interventions in Aging, 3, 263-272. https://doi.org/10.2147/CIA.S1846

[10] Gestrelius, S., Lyngstadaas, S.P. and Hammarström, L. (2000) Emdogain-Periodontal Regeneration Based on Biomimicry. Clinical Oral Investigations, 4, 120-125. https://doi.org/10.1007/s007840050127

[11] Bosshardt, D.D. and Nanci, A. (2004) Hertwig's Epithelial Root Sheath, Enamel Matrix Proteins, and Initiation of Cementogenesis in Porcine Teeth. Journal of Clinical Periodontology, 31, 184-192. https://doi.org/10.1111/j.0303-6979.2004.00473.x

[12] Hatakeyama, J., Sreenath, T., Hatakeyama, Y., Thyagarajan, T., Shum, L., Gibson, C.W., et al. (2003) The Receptor Activator of Nuclear Factor- $\kappa$ B Ligand-Mediated Osteoclastogenic Pathway Is Elevated in Amelogenin-Null Mice. Journal of Biolog- 
ical Chemistry, 278, 35743-35748. https://doi.org/10.1074/jbc.M306284200

[13] Haze, A., Taylor, A.L., Haegewald, S., Leiser, Y., Shay, B., Rosenfeld, E., et al. (2009) Regeneration of Bone and Periodontal Ligament Induced by Recombinant Amelogenin after Periodontitis. Journal of Cellular and Molecular Medicine, 13, 11101124. https://doi.org/10.1111/j.1582-4934.2009.00700.x

[14] Fukuda, T., Sanui, T., Toyoda, K., Tanaka, U., Taketomi, T., Uchiumi, T., et al. (2013) Identification of Novel Amelogenin-Binding Proteins by Proteomics Analysis. PLoS ONE, 8, e78129. https://doi.org/10.1371/journal.pone.0078129

[15] Toyoda, K., Fukuda, T., Sanui, T., Tanaka, U., Yamamichi, K., Atomura, R., et al. (2016) Grp78 Is Critical for Amelogenin-Induced Cell Migration in a Multipotent Clonal Human Periodontal Ligament Cell Line. Journal of Cellular Physiology, 231, 414-427. https://doi.org/10.1002/jcp.25087

[16] Du, P., Kibbe, W.A. and Lin, S.M. (2008) Lumi: A Pipeline for Processing Illumina Microarray. Bioinformatics, 24, 1547-1548.

https://doi.org/10.1093/bioinformatics/btn224

[17] Bolstad, B.M., Irizarry, R.A., Astrand, M. and Speed, T.P. (2003) A Comparison of Normalization Methods for High Density Oligonucleotide Array Data Based on Variance and Bias. Bioinformatics, 19, 185-193. https://doi.org/10.1093/bioinformatics/19.2.185

[18] Gentleman, R.C., Carey, V.J., Bates, D.M., Bolstad, B., Dettling, M., Dudoit, S., et al. (2004) Bioconductor: Open Software Development for Computational Biology and Bioinformatics. Genome Biology, 5, R80. https://doi.org/10.1186/gb-2004-5-10-r80

[19] Quackenbush, J. (2002) Microarray Data Normalization and Transformation. Nature Genetics, 32, 496-501. https://doi.org/10.1038/ng1032

[20] Huang, D.W., Sherman, B.T. and Lempicki, R.A. (2009) Systematic and Integrative Analysis of Large Gene Lists Using DAVID Bioinformatics Resources. Nature Protocols, 4, 44-57.

[21] Gillett, A., Maratou, K., Fewings, C., Harris, R.A., Jagodic, M., Aitman, T., et al. (2009) Alternative Splicing and Transcriptome Profiling of Experimental Autoimmune Encephalomyelitis using Genome-Wide Exon Arrays. PLoS ONE, 4, e7773. https://doi.org/10.1371/journal.pone.0007773

[22] Saeed, A.I., Sharov, V., White, J., Li, J., Liang, W., Bhagabati, N., et al. (2003) TM4: A Free, Open-Source System for Microarray Data Management and Analysis. BioTechniques, 34, 374-378.

[23] Cekici, A., Kantarci, A., Hasturk, H. and Van, Dyke, T.E. (2014) Inflammatory and Immune Pathways in the Pathogenesis of Periodontal Disease. Periodontology2000, 64, 57-80. https://doi.org/10.1111/prd.12002

[24] Guha, M. and Mackman, N. (2001) LPS Induction of Gene Expression in Human Monocytes. Cellular Signalling, 13, 85-94.

[25] Grandin, H.M., Gemperli, A.C. and Dard, M. (2012) Enamel Matrix Derivative: A Review of Cellular Effects in Vitro and a Model of Molecular Arrangement and Functioning. Tissue Engineering Part B: Reviews, 18, 181-202. https://doi.org/10.1089/ten.teb.2011.0365

[26] Rutherford, S.L. (2003) Between Genotype and Phenotype: Protein Chaperones and Evolvability. Nature Reviews Genetics, 4, 263-274. https://doi.org/10.1038/nrg1041

[27] Zhang, Y., Liu, R., Ni, M. and Lee, A.S. (2010) Cell Surface Relocalization of the Endoplasmic Reticulum Chaperone and Unfolded Protein Response Regulator GRP78/BiP. Journal of Biological Chemistry, 285, 15065-15075.

https://doi.org/10.1074/jbc.m109.087445 
[28] Spike, B.T., Kelber, J.A., Booker, E., Kalathur, M., Rodewald, R., Lipianskaya, J., et al. (2014) CRIPTO/GRP78 Signaling Maintains Fetal and Adult Mammary Stem Cells ex Vivo. Stem Cell Reports, 2, 427-439. https://doi.org/10.1016/j.stemcr.2014.02.010

[29] Ravindran, S., Narayanan, K., Eapen, A.S., Hao, J., Ramachandran, A., Blond, S., et al. (2008) Endoplasmic Reticulum Chaperone Protein GRP-78 Mediates Endocytosis of Dentin Matrix Protein 1. Journal of Biological Chemistry, 283, 29658-29670. https://doi.org/10.1074/jbc.m800786200

[30] Miron, R.J., Dard, M. and Weinreb, M. (2015) Enamel Matrix Derivative, Inflammation and Soft Tissue Wound Healing. Journal of Periodontal Research, 50, 555 569. https://doi.org/10.1111/jre.12245

[31] Simonini, A., Moscucci, M., Muller, D.W., Bates, E.R., Pagani, F.D., Burdick, M.D., et al. (2000) IL-8 Is an Angiogenic Factor in Human Coronary Atherectomy Tissue. Circulation, 101, 1519-1526. https://doi.org/10.1161/01.CIR.101.13.1519

[32] Okamura, H., Tsutsi, H., Komatsu, T., Yutsudo, M., Hakura, A., Tanimoto, T., et al. (1995) Cloning of a New Cytokine That Induces IFN- $\gamma$ Production by T Cells. Nature, 378, 88-91. https://doi.org/10.1038/378088a0

[33] Gosselin, E.J., Wardwell, K., Rigby, W.F. and Guyre, P.M. (1993) Induction of MHC Class II on Human Polymorphonuclear Neutrophils by Granulocyte/Macrophage Colony-Stimulating Factor, IFN-Gamma, and IL-3. Journal of Immunology, 151, 1482-1490.

[34] Ravanti, L., Häkkinen, L., Larjava, H., Saarialho-Kere, U., Foschi, M., Han, J., et al. (1999) Transforming Growth Factor-Beta Induces Collagenase-3 Expression by Human Gingival Fibroblasts via P38 Mitogen-Activated Protein Kinase. Journal of Biological Chemistry, 274, 37292-37300. https://doi.org/10.1074/jbc.274.52.37292

[35] Takashiba, S., Takigawa, M., Takahashi, K., Myokai, F., Nishimura, F., Chihara, T., et al. (1992) Interleukin-8 Is a Major Neutrophil Chemotactic Factor Derived from Cultured Human Gingival Fibroblasts Stimulated with Interleukin-1 Beta or Tumor Necrosis Factor Alpha. Infection and Immunity, 60, 5253-5258.

[36] Wang, P.L., Ohura, K., Fujii, T., Oido-Mori, M., Kowashi, Y., Kikuchi, M., et al. (2003) DNA Microarray Analysis of Human Gingival Fibroblasts from Healthy and Inflammatory Gingival Tissues. Biochemical and Biophysical Research Communications, 305, 970-973.

[37] Ara, T., Kurata, K., Hirai, K., Uchihashi, T., Uematsu, T., Imamura, Y., et al. (2009) Human Gingival Fibroblasts Are Critical in Sustaining Inflammation in Periodontal Disease. Journal of Periodontal Research, 44, 21-27. https://doi.org/10.1111/j.1600-0765.2007.01041.x 
Submit or recommend next manuscript to SCIRP and we will provide best service for you:

Accepting pre-submission inquiries through Email, Facebook, LinkedIn, Twitter, etc. A wide selection of journals (inclusive of 9 subjects, more than 200 journals)

Providing 24-hour high-quality service

User-friendly online submission system

Fair and swift peer-review system

Efficient typesetting and proofreading procedure

Display of the result of downloads and visits, as well as the number of cited articles Maximum dissemination of your research work

Submit your manuscript at: http://papersubmission.scirp.org/

Or contact ajmb@scirp.org 